\title{
Obituary: Professor Gerald Elliott
}

\author{
John M. Squire
}

Published online: 16 July 2013

(C) Springer Science+Business Media Dordrecht 2013

Professor Gerald Elliott, an eminent figure in the fields of muscle research and eye connective tissue research, died suddenly on March 6th, 2013 in hospital in Oxford, UK at the age of 82 . He is survived by his first wife, Deborah, a noted portrait photographer and gallerist, and their two sons Austin and Gavin, and by his second wife Dr. Katalin Pinter, a Hungarian biochemist and molecular biologist.

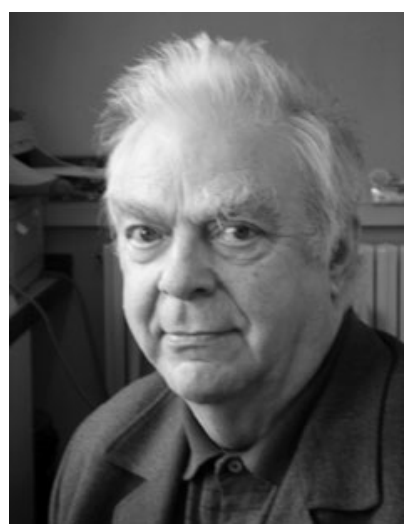

\section{The early years}

Gerald was born in Eltham, South East London, UK, on January 26th, 1931, one of five children of a successful city

For an extended version of this obituary, please refer to the electronic supplementary material.

Electronic supplementary material The online version of this article (doi:10.1007/s10974-013-9354-9) contains supplementary material, which is available to authorized users.

J. M. Squire $(\square)$

Muscle Contraction Group, University of Bristol, Bristol, UK

e-mail: j.squire@imperial.ac.uk; j.m.squire@bristol.ac.uk solicitor. He attended Eltham College. Sadly his father's business was badly affected by the war and they lost almost everything including their home. Gerald carried out his National Service as a subaltern in the Royal Electrical and Mechanical Engineers (REME), before going up in 1951 to Lincoln College, Oxford where he read Physics. While Gerald was an undergraduate, the historic papers on the structure of DNA by Watson and Crick (1953) in Cambridge and Wilkins et al. (1953), Franklin and Gosling (1953) at King's College London were published. Gerald read these in his final year as an undergraduate and they inspired him to apply to King's for a research position. At that time the Head of Physics was the diminutive and dapper J.T. Randall (JT), famed in the war for his work with H.R. Boot on radar. In Gerald's own words (Elliott 2007a):

He (JT) and H.R. Boot had revolutionised microwave radar by strapping the anodes of the cavity magnetron so that it operated only in the fundamental mode. This created the technology that JT regularly like to tell us had won the war.

Since he had been in REME, Gerald was able to talk knowledgeably to JT about the AA3 MK7 anti-aircraft radar set, an experience which he believed helped him to get the position of demonstrator in Physics in JT's Department. Even before the war, JT had believed in the importance of applying physical methods and thinking to biological problems. He followed this up after the war briefly as Head of Physics at St Andrews University and then in 1946 he was appointed as Wheatstone Professor of Physics at King's College London. There his Department on the Strand became the only UK Physics Department to study Biophysics. Through his efforts and the support of the Royal Society, the MRC and (controversially at the 
time) the Rockefeller Foundation in America, they gradually acquired some of the best equipment available; excellent light microscopes, an electron microscope and $\mathrm{X}$-ray diffraction equipment. The X-ray equipment provided the experimental data obtained by Rosalind Franklin and Maurice Wilkins on which Watson and Crick based their new model of DNA. Eventually, largely through JT's own efforts, Biophysics within the Physics Department led to King's College having the first separate Biophysics Department in the UK. JT was the first Head of this new Department, which moved to the well-known Drury Lane laboratory in 1963 (later to became the Randall Institute), taking along those staff, like Maurice Wilkins and Gerald, who were working on physics applied to biology. Part of this group included Jean Hanson (later FRS), who in 1954, with Hugh Huxley (also later FRS), had written one of the two seminal papers on the sliding filament model of muscle contraction (Huxley and Hanson 1954). The second paper was by Andrew Huxley (later Nobel Laureate, Professor Sir Andrew Huxley FRS OM) and Rolf Niedergerke (Huxley and Niedergerke 1954). These two papers showed that the vertebrate muscle sarcomere contains separate myosin and actin filaments which slide past each other when a muscle shortens and that this sliding occurs without large changes in the lengths of the filaments. To quote Gerald again (Elliott 2007a):

In the light of the 1954 papers, the overwhelming question became how the two sets of filaments move past one another and generate tension during contraction. This would require an answer compatible with physics and chemistry, though subtleties could surely have arisen in more than 3 billion years of biological evolution. Attention quickly focussed on the cross-bridges between the two sets of filaments, first observed in electron microscope thin sections by Hugh Huxley (Huxley 1957), who had also done pioneering one-dimensional low-angle X-ray (diffraction) studies of living muscle (Huxley 1953).

Although JT was officially his supervisor, Gerald ended up working for Jean Hanson. Jean trained as a classical biologist, was instrumental with others in teaching biology to Gerald and his fellow non-biologists, but Gerald felt that his own background as a 'brash' physicist led to some disagreements. In his PhD work at King's Jean Hanson really wanted Gerald to do electron microscopy, but for Gerald, impressed with the DNA story based on the King's $\mathrm{X}$-ray diffraction data, his priority was to do X-ray diffraction of muscle. Despite their differences, Gerald acknowledged Jean Hanson's open-mindedness, her loyalty, and her total support when it came to asking JT for $\mathrm{X}$-ray diffraction equipment for Gerald to study muscle. Jean was much loved and respected by her colleagues and, apart from her contribution to the sliding filament model, she made major advances in other areas, including her seminal electron microscopy of actin filaments with Jack Lowy which revealed the twisting helical arrangement of the actin subunits with which we are now so familiar (Hanson and Lowy 1963). Sadly Jean died very unexpectedly in 1973 and this led Gerald to comment many years later:

I have often pondered where it (her research) might have led her had she lived. In my opinion-though of course I am biased-Jean had the most flexible mind of those four sliding filament pioneers. I sometimes wonder if she could perhaps have made great breakthroughs in a muscle field that has-at least in my view-sadly become rather stagnant.

This remark expresses Gerald's general feeling about the muscle field to which he made such major contributions. Later in life he became known as something of a 'disgruntled maverick' in the field. How did this arise? Sadly the seeds for this were sown at quite an early stage. Gerald's successful $\mathrm{PhD}$ work was on the X-ray diffraction and electron microscopy of molluscan smooth muscles (the 'muscles of mussels') which have large paramyosin-containing filaments rather than the myosin filaments in vertebrate muscles. Among many other important observations he found from the electron microscopy of cross-sections of the Portuguese Oyster (Gryphaea angulata) opaque adductor muscle that the thick paramyosin filaments sometimes showed parallel stripes of staining as though the filaments contained layers of paramyosin molecules. Since it was thought that these filaments also contained myosin, probably as a roughly cylindrical layer on the whole surface of the paramyosin core (Squire 1971), the presence of a layered core structure rather than one with circular symmetry in cross-section was surprising; the myosin rods would make many different contacts with the underlying paramyosin layer structure, sometimes on a front face with the so-called 'Bear-Selby net' structure, sometimes on an edge, and sometimes on a 'Bear-Selby net' at the back with opposite hand (Bear and Selby 1956).

When Gerald had completed his PhD thesis in 1960 he suggested to JT that Hugh Huxley would be the best choice for an external examiner. However, JT in his wisdom, instead of asking Hugh Huxley, decided to ask the unrelated Andrew Huxley (Cambridge Physiology, soon to move to University College London, UCL). Andrew, the other main sliding filament hero, was known as the most feared 'inquisitor' of his generation, as anyone who gave a seminar at UCL Physiology in the $60 \mathrm{~s}$ or $70 \mathrm{~s}$ could testify. Thus Gerald turned up to be faced with one of the greatest scientific brains of the twentieth century, an 'about to be' Nobel Prize winner, got hauled over the coals line by line for hours and hours, and had to do a major re-write. In 


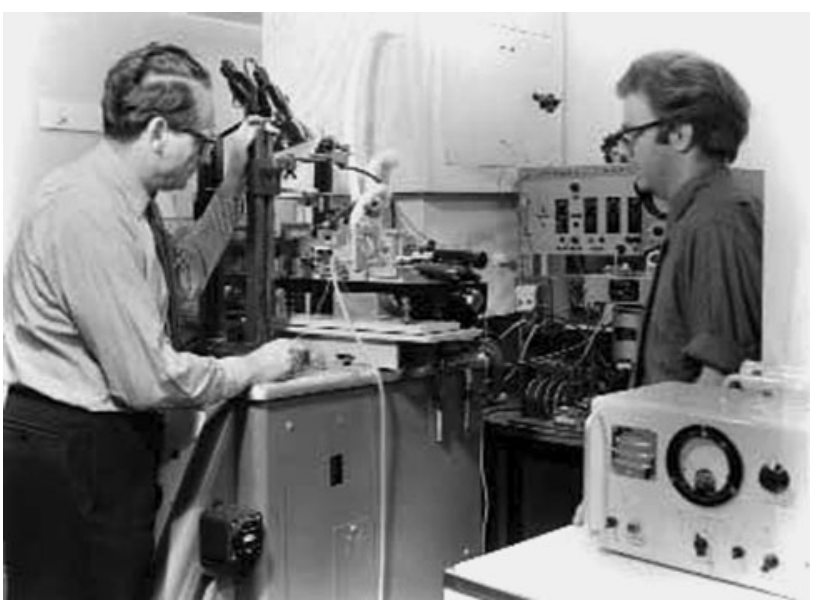

Gerald with one of his early collaborators the physiologist Jack Lowy, discoverer with Jean Hanson of the subunit structure of F-actin (Hanson and Lowy 1963). Here they are using a fixed anode X-ray generator and a Franks camera (together with some physiological equipment)

particular, Andrew, commenting on the thesis work, reckoned that the layers seen in paramyosin filament crosssections ought to be visible in some longitudinal sections, but were apparently never seen. He didn't like Gerald's conclusion, but, with some caveats, in 1960 the thesis was finally finished (Elliott 1960).

Something like two decades later it turned out that Gerald's ideas on molluscan muscle paramyosin filaments were probably correct. Arthur Elliott (no relation-but another well-known King's London Biophysicist) and Pauline Bennett in the late 1970s and early $80 \mathrm{~s}$ carried out detailed electron microscopy and high-angle X-ray diffraction of isolated molluscan paramyosin filaments and came to the conclusion that the paramyosin molecules pack in a sort of 3-dimensional crystal through the filaments (Elliott 1979; Elliott and Bennett 1984). According to Gerald's son Austin Elliott:

Gerald used to say, a bit wistfully "Years later it turned out I was right after all... but no-one noticed". Given that Andrew Huxley was probably the key scientific 'antagonist' of Gerald's career, you could see the viva as rather setting the tone...

\section{Pioneering X-ray diffraction studies of muscle}

Gerald had come to realise that the combination of the complementary techniques of electron microscopy and $\mathrm{X}$-ray diffraction would be very powerful, so in the late 1950s he started working with Roy Worthington, who had just arrived from Australia and with whom he was to have a life-long collaboration. They set up a two-dimensional low- angle X-ray camera, suitable for recording the rather large molecular spacings (up to several tens of $\mathrm{nm}$ ) that are found in muscle. The new camera was one based on the mirror-focussing device of Kirkpatrick and Baez (father of Joan) which had been further developed for metallurgy by Albert Franks (Franks 1955). Such a camera was used successfully in a series of experiments (Elliott and Lowy 1961; Elliott 1964; Millman and Elliott 1965) to define the axial and equatorial periodicities from a number of muscle types (i.e. striated muscles from frog, rabbit, catch muscles from oyster, vertebrate smooth muscle from guinea pig) in static states such as relaxed or rigor. In particular it was noted that:

(1) The axial periodicities in the muscles did not change as the muscle's length was changed (as required by the sliding filament model).

(2) The volume of the muscle lattice stayed more or less constant as the sarcomere length was changed (confirming an earlier suggestion by Hugh Huxley).

(3) The intensity of part of the equatorial X-ray pattern, namely the $(1,1)$ peak, gradually reduced as the sarcomere length increased, consistent with the actin filaments being gradually withdrawn from the hexagonal A-band lattice in vertebrate muscles, once again as required in the sliding filament model.

(4) Parts of the diffraction patterns ascribed to actin and myosin filaments had different axial spacings in patterns from vertebrate skeletal muscles, and also from molluscan muscles, but the axial spacings of the myosin and actin filaments appeared similar or related in patterns from insect flight muscle.

Having carried out these successful studies of resting or rigor muscles, Gerald then wanted to study actively contracting muscle in a time-resolved way and was very ingenious in using the available $\mathrm{X}$-ray generator to best advantage. X-rays are produced in conventional X-ray generators by bombarding a metal target (the anode) with a beam of high-speed electrons from a heated filament, the whole system being encased in an evacuated chamber with Beryllium windows through which the X-rays can pass. The problem with this method is that most of the energy of the electrons appears as heat in the water-cooled target and if the electron beam current is too high the anode will melt. How to get a more intense X-ray beam without melting the anode? Gerald remembered a story he had heard from a much-decorated REME instructor "who had told me how he had driven a damaged truck without a cooling system out of the firing line in Normandy. 'It meant I had to replace the engine' the instructor said' but at least I could do it without the $b^{* * * * * * s}$ shooting at me.' What Gerald did was to run the generator at $3 \mathrm{~mA}$, rather than the normal $400 \mu \mathrm{A}$, but only for a short time. The anode would 
melt if the system was run at $3 \mathrm{~mA}$ for more than $2 \mathrm{~s}$, so he ran the experiment for a second or so and then turned the electron beam off. After a while this could be repeated in a 'stroboscopic' experiment so that enough diffracted intensity from an active muscle could be built up over time. To do these experiments in the early 1960s, after Roy Worthington had departed for a job in America, Gerald collaborated with the physiologist Jack Lowy (the one who with Jean Hanson also visualised the actin filament helix for the first time in around (Hanson and Lowy 1963). Gerald was later joined by Barry Millman, a Canadian who had finished his $\mathrm{PhD}$ on the physiology of molluscan muscles with Jack, and together Gerald and Barry worked on molluscan and vertebrate muscles in the contracting state. So by the mid-1960s Gerald and his collaborators were ready to publish their findings on active vertebrate striated muscle. Meanwhile Hugh Huxley in Cambridge had been following up his own earlier work on the X-ray diffraction of vertebrate muscle with similar time-resolved studies of the active state. After some negotiations between King's and Cambridge it was agreed that the two papers would be published back to back in Nature (see detailed comments on the history of this in Elliott 2007a, b).

The two 1965 Nature papers (Elliott et al. 1965; Huxley et al. 1965) were both milestones, being the first X-ray diffraction papers on active vertebrate striated muscle. They showed clearly that: (i) the filament axial spacings did not change significantly between relaxation and full activity, (ii) that the equatorial $(1,1)$ reflection became much stronger in patterns from active muscle relative to the $(1,0)$ reflection, consistent with increase of mass at the actin filament positions (Gerald's team only), (iii) that the layer-lines from the myosin filaments, apart from those with intensity on the meridian, reduced in intensity when the muscle was active, indicating the movement of myosin cross-bridges and (iv) that the lattice spacing between myosin filaments changed with sarcomere length in the same sort of way in both resting and active muscle (as required for constant volume), although the active spacing was slightly smaller than the relaxed spacing (Gerald's team only).

At this point, then, Gerald and his collaborators were pioneers in the muscle field on a virtually equal footing with the Cambridge group. They did publish more on active muscle (Elliott 1967; Elliott et al. 1967), but Hugh Huxley then gained the initiative primarily by developing improved X-ray techniques (see Huxley 2008). Eventually this led Hugh Huxley (with W. Brown) to publish his monumental and comprehensive work in 1967 "The LowAngle X-ray Diagram of Vertebrate Striated Muscle and its Behaviour during Contraction and Rigor" (Huxley and Brown 1967), a remarkable 51 page treatise in the Journal of Molecular Biology, which laid the foundation for all

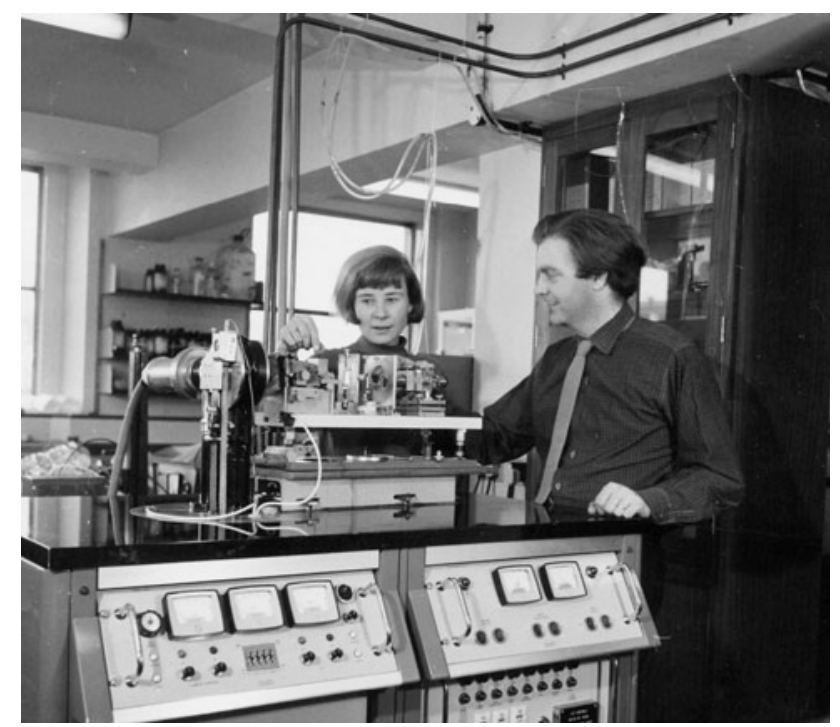

Gerald with his colleague Liz Rome and their relatively new rotating anode X-ray generator, still with a Franks camera

subsequent X-ray diffraction studies of muscle (apart from the equator). In the meantime, Gerald had pioneered the study of the equator of the X-ray pattern and the analysis of the constant volume behaviour of the muscle lattice. This led him into thinking about how the muscle lattice was maintained by electrostatic (repulsive) and van der Waals (attractive) forces (Elliott 1968) between myosin filaments. $\mathrm{He}$ was able to show that the lattice spacing between myosin filaments observed at long sarcomere lengths, when the actin filaments were virtually absent from the A-band lattice, could be explained quite well by this kind of force balance. With Mike Spencer and Liz Rome he then went on to speculate about the possible role of such force balances in the generation of muscular force (Elliott et al. 1970). It is notable that his ideas about force balances between parallel cylinders came into play again with his later studies of collagen fibrils in the cornea of the eye.

During this time in London Gerald was not just working on muscle. He was a School Governor at Dulwich College where he gave talks to encourage the boys to go into science. He also had a life-long interest in socialist and social democratic politics and stood for Parliament as a Labour candidate for Croydon North East in 1966 and 1970, narrowly losing to Bernard Weatherill, later speaker in the House of Commons and to become Lord Weatherill.

\section{Off to America}

In 1967 Gerald obtained a position at the Carnegie-Mellon University in Pittsburgh, Pennsylvania where he was appointed Professor of Chemistry and Biology. Here Gerald continued his X-ray studies of muscle as well as 
electron microscopy and laser diffraction, all in the interest of investigating the constant volume behaviour of muscle (April et al. 1971, 1972). He and his colleagues showed first that muscles of the walking legs of the crayfish $(\mathrm{Or}$ conectes) displayed constant volume behaviour, even after the sarcolemma had been removed, so that this appeared to be an intrinsic property of the myofilament lattice. They also showed that with skinned fibres the lattice spacing could be altered by changes in ionic strength and $\mathrm{pH}$ in a manner that was consistent with these changes altering the electrostatic forces between the filaments as in a liquidcrystalline solution. It is notable that Gerald's first postDoc at Pittsburgh was Ada Yonath who was later (2009) to win the Nobel Prize in Chemistry for her work on the structure of the ribosome.

During this period in the US Gerald and his family also spent three idyllic summers at the Marine Biology Institute at Woods Hole, a favourite summer meeting place for US muscle researchers and others.

\section{The Open University}

After Pittsburgh, Gerald moved back to the UK where he was appointed the founding Professor of Physics in the Open University (OU). He was at the OU from 1969 until his formal retirement in 1996. The OU was then relatively new and had no research facilities for Gerald, so through the good offices of Jean Hanson he spent a good bit of his time back at the Drury Lane Biophysics laboratory. There he had fruitful collaborations with Barry Millman, Carl Moos and the Japanese physiologist Ichiro Matsubara. Gerald and Ichiro found that, unlike the crayfish, intact frog semi-tendinosus muscles showed constant volume behaviour, but skinned fibres did not; the sarcolemma is necessary to maintain the constant volume (Elliott and Matsubara 1972). This was explained in terms of Donnan and osmotic equilibria across the sarcolemma. He also continued his work on active muscle (Millman and Elliott 1972). During this time Gerald also contributed to a number of OU undergraduate courses.

Eventually Gerald set up his own Biophysics unit in Oxford first at Bevington Road and then at the OU Oxford Research Unit at Boars Hill. He became Director of that unit in 1989. At Boars Hill one of his first recruits was Julia Goodfellow, later to become Chief Executive of the UK Biotechnology and Biological Sciences Research Council (BBSRC) and now Professor Dame Julia M Goodfellow DBE, CBE, FMedSci, FInstP, Vice Chancellor of the University of Kent. He also continued to study the electrostatic interactions between muscle filaments and electrical phenomena in the filament lattice during contraction continued in earnest. With Else Bartels and others in the 1970s and $80 \mathrm{~s}$, he measured Donnan potentials in skinned fibres using micro-electrodes (Elliott 1973a, b, 1980; Elliott and Bartels 1982; Elliott et al. 1984; Bartels and Elliott 1985; Naylor et al. 1985). At this stage Gerald also teamed up again with his old muscle collaborator Jack Lowy after Jack had retired from his Professorship in Aarhus, Denmark and had returned to the UK (see Elliott 2000). Among other things, they attempted, with Jack's colleague Finn Poulsen, to analyse the diffuse scatter observed in X-ray diffraction patterns (e.g. Poulsen et al. 1987), an exceedingly difficult task.

Although Gerald's first love was the mechanism of muscle contraction, in the late 1950s he became convinced that electrical charges also play an important role in maintaining the lateral packing of collagen fibrils in the cornea, which is crucial to its optical transparency. So it was at this Oxford Research Unit that Gerald started in earnest on his research into the structure of the transparent tissues of the eye, particularly the cornea and the lens, a topic which he found he could fund more easily than his work on muscle, despite applying similar physical insights and similar experimental techniques in both research fields. It was a puzzle to him why this was so, and it caused a good deal of frustration. In fact Gerald was the first to correctly interpret the X-ray diffraction pattern from the cornea. This work led to two successive NIH grants, and several ground-breaking publications. Gerald's ideas about the polyelectrolytic nature of the cornea and maintenance of transparency have long been accepted, and are seen as mainstream within the eye field (Elliott et al. 1980; Sayers et al. 1982).

At the Oxford Research Unit he also recruited Keith Meek, now Professor and Head of the Biophysics Research Group in the School of Optometry and Vision Science at

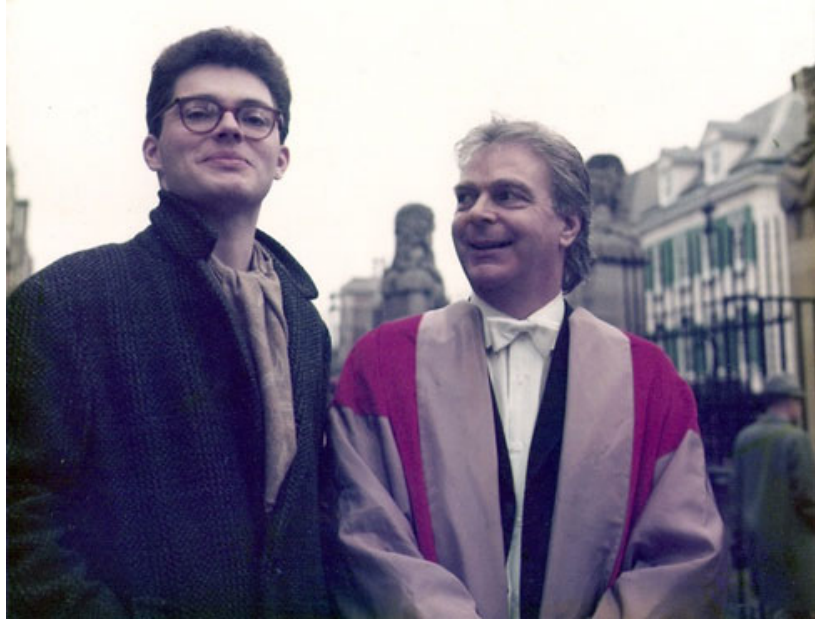

Gerald with his son Austin just outside the Radcliffe Camera in Oxford at the time of the award of Gerald's DSc in 1984 
Cardiff University. After Gerald retired from the OU, from 1997 to 2005 he was appointed as Distinguished Research Fellow in Vision Sciences in this group at Cardiff where he continued his successful eye research with Keith Meek and others, including Justyn Regini, one of Gerald's later OU $\mathrm{PhD}$ students, who became a kind of protégé. Gerald retained the title of Emeritus Professor of Physics at the OU, was an Associate Fellow at Green Templeton College and an Honorary Research Associate in the Nuffield Laboratory of Ophthalmology, Oxford.

\section{Gerald's last muscle theories}

Throughout the period from 1994 to 2012 Gerald and his old friend and collaborator Roy Worthington published a series of papers on the mechanism of contraction in muscle (Elliott and Worthington 1994, 1997, 2000, 2001, 2012; Worthington and Elliott 1996a, b, 2003, 2005). Their ideas were radically different from the conventional swinging cross-bridge hypothesis, but they found it very hard to get a good hearing. Their last joint paper, published as recently as 2012 (Elliott and Worthington 2012) has a title that starts "Along the road not taken ......", a reference to the poem by Robert Frost that was later read at Gerald's funeral service. The poem concludes:

Two roads diverged in a wood, and I, I took the one

less travelled by, and that has made all the difference

So Gerald and Roy had different ideas from the 'conventional' view of muscle. They thought that this caused them to lose out on muscle grant funding and they found it hard to publish their ideas in the mainstream muscle literature. But do they have a point? Maybe now is not the time or place to make a judgement. But there are one or two things highlighted in these papers that perhaps should make us stop and think, whatever the ultimate value of their theory of contraction. For example they cite the paper by Lionne et al. (1996) which shows well-documented results that appear to contradict the conventional theory of 'independent force generators throughout the A-band'. The conventional view of muscle is that the myosin heads act as independent force generators, so that, for example, the total isometric force that a muscle can generate reduces linearly as the amount of filament overlap reduces when the sarcomere length increases beyond rest length at about 2.1 or $2.2 \mu \mathrm{m}$ (Gordon et al. 1966). Related experiments on ATP usage as a function of sarcomere length also show a drop as the filament overlap reduces (He et al. 1997). One might expect that ATP usage during unloaded muscle shortening might also depend on sarcomere length in the same way. In other words, the total ATP usage in going from a long length to a fixed shorter length $\left(\mathrm{ATP}_{\mathrm{c}}\right)$ might be expected to be higher if the shortening starts from a longer sarcomere length rather than a shorter one. This does not appear to be the case in the experiments of Lionne et al. (1996) as pointed out by Gerald and Roy. Figure 2 in Lionne et al. (reproduced in Elliott and Worthington 2012) illustrates their experiment where ATP usage was monitored in myofibrils that were allowed to undergo unloaded shortening from two different sarcomere lengths, 2.8 and $3.5 \mu \mathrm{m}$. In both cases there was a very fast early phosphate burst, followed by a rapid phase during the shortening itself which then changes abruptly to a slower phase when the shortening had stopped or was much reduced. Lionne et al. studied the size of the phosphate burst and of ATPc for fibrils shortening from a range of different starting sarcomere lengths down to a common shorter length. Apparently in contradiction to the conventional wisdom, the size of the phosphate burst and of ATPc were more or less constant for starting sarcomere lengths over the range from 2.7 to $3.5 \mu \mathrm{m}$. As Lionne et al. themselves say: "From a purely enzymatic point of view the situation is difficult to understand; we have made several attempts at fitting it to classical ATPase schemes, but without success."

The take home message from Gerald is, I think, that we should be more open minded in the muscle research field, that we should not necessarily believe everything that we are told or read about in the published literature, that we should question, question, question the current 'wisdom' all the time, that there should be space in the field for those with alternative views, and that funding of grants should not depend on whether or not the applicant supports the 'party' line. How often in published muscle papers do people interpret their observations in terms of the current wisdom, the swinging crossbridge theory, without at the same time wondering how else the same data could be explained and then providing reasons to choose between the alternatives. We really need to do this! I once made this point to a senior muscle researcher who replied "But that's really hard, John". My unspoken response to this was: 'But that is what scientists are supposed to do isn't it! Is the muscle field somehow different?'

Building on Gerald's convictions, let me give examples of what I mean. When I came into the muscle field in the late 1960s it was thought that the myosin filaments in vertebrate striated muscles and insect flight muscles were all 2-stranded (Huxley and Brown 1967; Reedy 1968). I looked at the data on which this was based and realised (Squire 1971) that the number of strands could be more, and could be different for different muscle types, which turned out to be the case; vertebrate striated muscle myosin filaments are 3-stranded and insect flight muscle myosin filaments are 4-stranded. Secondly, when David Parry and I did our work on the steric blocking model of thin filament regulation (Parry and Squire 1973), we didn't just say that 
the X-ray data on this could be explained by a shift of tropomyosin in the grooves of the actin filament. We also said to ourselves: 'If it is not a tropomyosin shift then what else could it be?' We then tested all the alternatives that we could think of and found that the tropomyosin shift was really the only model that would work. It is exactly this kind of alternative thinking which Gerald was always pushing for. I could go on with many more examples, but suffice it to give one more. Recently the interference effects on the meridian of X-ray diffraction patterns from vertebrate striated muscles (e.g. Piazzesi et al. 2002; Reconditi et al. 2004; Huxley et al. 2006a, b and many more) were interpreted almost entirely in terms of movements of the lever arms of the myosin heads. It was not until others looked at alternative interpretations of these observations (Knupp et al. 2009) that it was shown these observed effects were almost entirely due to relative movements of the motor domains of the myosin heads, some attached to actin and some detached, and that sadly these intensities revealed little about the behaviour of the lever arms. It is this kind of testing of alternatives that we should be doing all the time if we don't want to lead ourselves down blind alleys, and it is what we need to do to take the field forward. I am convinced, like Gerald, that several ideas that we all hold as central to our current concepts on the mechanism of muscle contraction will not stand up to detailed scrutiny. This critical approach was Gerald's philosophy, and as he himself put it in one particular example: "I think that any graduate student who agrees with their supervisor on all points is probably in the wrong game!" This sums up his very healthy attitude to science and is one that we in the muscle field would be foolish not to follow. The field has been stuck in a rut for long enough.

To conclude, here are some further comments from Professor Caroline Pond, Gerald's OU colleague and friend, and Gerald's son Austin Elliott:

Caroline: Gerald was a cheerful, gregarious character who enjoyed working with all sorts of people, especially women whose roles as serious scientists he greatly admired. He was always quick to acknowledge the diverse contributions of his many collaborators: he is sole author on only a handful of more than 100 publications. Although his concepts, particularly on crossbridges, failed to become mainstream, he never allowed his desire for personal popularity to attenuate his insistence upon the awkward implications of rigorously performed measurements.

Austin: Gerald's interest in muscle research lasted to the end of his life: his last e-mail before his death was to Hugh Huxley, who he had known since the 1950s. Though disappointed that his final exposition of his concept of muscle contraction published early last year (Elliott and Worthington 2012) did not elicit more discussion, he remained philosophical. 'Time will tell.' He would say.

Acknowledgments Various people who knew Gerald well have contributed to parts of this obituary, especially his wife Katalin and son Austin, and some of his collaborators and friends including Professor Belinda Bullard, Professor K.W. Ranatunga, Professor Caroline Pond, Professor Keith Meek and Dr. Justyn Regini. I am grateful to them all, as I am to have known and interacted with Gerald who enriched all our lives.

\section{References}

April EW, Brandt PW, Elliott GF (1971) The myofilament lattice: studies on isolated fibers. I. The constancy of the unit-cell volume with variation in sarcomere length in a lattice in which the thin-to-thick myofilament ratio is 6:1. J Cell Biol 51:72-82

April EW, Brandt PW, Elliott GF (1972) The myofilament lattice: studies on isolated fibers. II. The effects of osmotic strength, ionic concentration, and $\mathrm{pH}$ upon the unit-cell volume. J Cell Biol 53:53-65

Bartels EM, Elliott GF (1985) Donnan potentials from the A- and I-bands of glycerinated and chemically skinned muscles, relaxed and in rigor. Biophys $\mathrm{J} 48: 61-76$

Bear RS, Selby CC (1956) The structure of paramyosin fibrils according to X-ray diffraction. J Biophys Biochem Cytol 2:55-85

Elliott GF (1960) Electron microscope and X-ray diffraction studies of invertebrate muscle fibres. PhD Thesis, University of London

Elliott GF (1964) X-ray diffraction studies on striated and smooth muscles. Proc R Soc Lond B Biol Sci 160:467-472

Elliott GF (1967) Variations of the contractile apparatus in smooth and striated muscles: X-ray diffraction studies at rest and in contraction. J Gen Physiol 50(Suppl):171-184

Elliott GF (1968) Force-balances and stability in hexagonally-packed polyelectrolyte systems. J Theor Biol 21:71-87

Elliott GF (1973a) Donnan and osmotic effects in muscle fibres without membranes. J Mechanochem Cell Motil 2:83-89

Elliott GF (1973b) The muscle fiber: liquid-crystalline and hydraulic aspects. Ann N Y Acad Sci 204:564-574

Elliott A (1979) Structure of molluscan thick filaments: a common origin for diverse appearances. J Mol Biol 132:323-341

Elliott GF (1980) Measurements of the electric charge and ionbinding of the protein filaments in intact muscle and cornea, with implications for filament assembly. Biophys J 32:95-97

Elliott GF (2000) Professor Jack Lowy. J Muscle Res Cell Motil 21:715-716

Elliott GF (2001) Worthington CR (2000) Muscle contraction: viscous-like frictional forces and the impulsive model. Int $\mathrm{J}$ Biol Macromol 27: 327-332. Corrected and republished in. Int J Biol Macromol 29:213-218

Elliott GF (2007a) X-rays, twitching muscles and burning anodes. Physiol News 67:6-10

Elliott GF (2007b) Living history. Physiol News 69:42

Elliott GF, Bartels EM (1982) Donnan potential measurements in extended hexagonal polyelectrolyte gels such as muscle. Biophys J 38:195-199

Elliott A, Bennett PM (1984) Molecular organization of paramyosin in the core of molluscan thick filaments. J Mol Biol 176:477-493

Elliott GF, Lowy J (1961) Low-angle X-ray reflections from living molluscan muscles. J Mol Biol 3:41-46 
Elliott GF, Matsubara I (1972) The constant-volume behaviour of the myofilament lattice in frog skeletal muscle: studies on skinned and intact single fibres by X-ray and light diffraction. J Physiol 226:88P-89P

Elliott GF, Worthington CR (1994) How muscle may contract. Biochim Biophys Acta 1200:109-116 Review

Elliott GF, Worthington CR (1997) The muscle motor: 'simultaneous' levers or sequential impulses? Int J Biol Macromol 21:271-275 Review

Elliott GF, Worthington CR (2001) Muscle contraction: viscous-like frictional forces and the impulsive model. Int J Biol Macromol 29:213-218

Elliott GF, Worthington CR (2012) Along the road not taken: how many myosin heads act on a single actin filament at any instant in working muscle? Prog Biophys Mol Biol 108:82-92

Elliott GF, Lowy J, Millman BM (1965) X-ray diffraction from living striated muscle during contraction. Nature 206:1357-1358

Elliott GF, Lowy J, Millman BM (1967) Low-angle X-ray diffraction studies of living striated muscle during contraction. J Mol Biol 25:31-45

Elliott GF, Rome EM, Spencer M (1970) A type of contraction hypothesis applicable to all muscles. Nature 226:417-420

Elliott GF, Goodfellow JM, Woolgar AE (1980) Swelling studies of bovine corneal stroma without bounding membranes. J Physiol 298:453-470

Elliott GF, Bartels EM, Cooke PH, Jennison K (1984) A reply to Godt and Baumgarten's potential and $\mathrm{K}+$ activity in skinned muscle fibers: evidence for a simple Donnan equilibrium under physiological conditions. Biophys J 45:487-488

Franklin RE, Gosling RG (1953) Molecular configuration in sodium thymonucleate. Nature 171:740-741

Franks A (1955) An optically focussing X-ray diffraction camera. Proc Phys Soc B68:1054-1064

Gordon AM, Huxley AF, Julian FJ (1966) The variation in isometric tension with sarcomere length in vertebrate muscle fibres. J Physiol 184:170-192

Hanson J, Lowy J (1963) Structure of F-actin and of actin filaments isolated from muscle. J Mol Biol 6:46-60

He ZH, Chillingworth RK, Brune M, Corrie JE, Trentham DR, Webb MR, Ferenczi MA (1997) ATPase kinetics on activation of rabbit and frog permeabilized isometric muscle fibres: a real time phosphate assay. J Physiol 501:125-148

Huxley HE (1953) X-ray analysis and the problem of muscle. Proc R Soc Lond B Biol Sci 141:59-62

Huxley HE (1957) The double array of filaments in cross-striated muscle. J Biophys Biochem Cytol 3:631-648

Huxley HE (2008) Memories of early work on muscle contraction and regulation in the 1950's and 1960's. Biochem Biophys Res Commun 369:34-42

Huxley HE, Brown W (1967) The low-angle X-ray diagram of vertebrate striated muscle and its behaviour during contraction and rigor. J Mol Biol 30:383-434

Huxley HE, Hanson J (1954) Changes in the cross-striations of muscle during contraction and stretch and their structural interpretation. Nature 173:973-976

Huxley AF, Niedergerke R (1954) Structural changes in muscle during contraction; interference microscopy of living muscle fibres. Nature 173:971-973

Huxley HE, Brown W, Holmes KC (1965) Constancy of axial spacings in frog Sartorius muscle during contraction. Nature 206:1358
Huxley HE, Reconditi M, Stewart A, Irving T (2006a) X-ray interference studies of crossbridge action in muscle contraction: evidence from quick releases. J Mol Biol 363:743-761

Huxley HE, Reconditi M, Stewart A, Irving T (2006b) X-ray interference studies of crossbridge action in muscle contraction: evidence from muscles during steady shortening. J Mol Biol 363:762-772

Knupp C, Offer G, Ranatunga KW, Squire JM (2009) Probing muscle myosin Motor action: $\mathrm{x}$-ray (m3 and $\mathrm{m} 6)$ interference measurements report motor domain not lever arm movement. J Mol Biol 390:168-181

Lionne C, Travers F, Barman T (1996) Mechanochemical coupling in muscle: attempts to measure simultaneously shortening and ATPase rates in myofibrils. Biophys J 70:887-895

Millman BM, Elliott GF (1965) X-ray diffraction from contracting molluscan muscle. Nature 206:582-824

Millman BM, Elliott GF (1972) An x-ray diffraction study of contracting molluscan smooth muscle. Biophys J 12:1405-1414

Naylor GR, Bartels EM, Bridgman TD, Elliott GF (1985) Donnan potentials in rabbit psoas muscle in rigor. Biophys J 48:47-59

Parry DAD, Squire JM (1973) Structural role of tropomyosin in muscle regulation: analysis of the $\mathrm{X}$-ray diffraction patterns from relaxed and contracting muscles. J Mol Biol 75:33-55

Piazzesi G, Reconditi M, Linari M, Lucii 1, Sun Y-B, Narayanan T, Boesecke P, Lombardi V, Irving M (2002) Mechanism of force generation by myosin heads in skeletal muscle. Nature 415:659-662

Poulsen FR, Lowy J, Cooke PH, Bartels EM, Elliott GF, Hughes RA (1987) Diffuse X-ray scatter from myosin heads in oriented synthetic filaments. Biophys J 51:959-967

Reconditi M, Linari M, Lucii L, Stewart A, Sun YB, Boesecke P, Narayanan T, Fischetti RF, Irving T, Piazzesi G, Irving M, Lombardi V (2004) The myosin motor in muscle generates a smaller and slower working stroke at higher load. Nature 428:578-581

Reedy MK (1968) Ultrastructure of insect flight muscle. I. Screw sense and structural grouping in the rigor cross-bridge lattice. J Mol Biol 31:155-176

Sayers Z, Koch MH, Whitburn SB, Meek KM, Elliott GF, Harmsen A (1982) Synchrotron X-ray diffraction study of corneal stroma. J Mol Biol 160:593-607

Squire JM (1971) General model for the structure of all myosincontaining filaments. Nature 233:457-462

Watson JD, Crick FHC (1953) A structure for deoxyribose nucleic acid. Nature 171:737-738

Wilkins MHF, Stokes AR, Wilson HR (1953) Molecular structure of deoxypentose nucleic acids. Nature 171:738-740

Worthington CR, Elliott GF (1996a) The step-size distance in muscle contraction: properties and estimates. Int $\mathrm{J}$ Biol Macromol 19:287-294

Worthington CR, Elliott GF (1996b) Muscle contraction: the step-size distance and the impulse-time per ATP. Int J Biol Macromol 18:123-131

Worthington CR, Elliott GF (2003) Muscle contraction: energy rate equations in relation to efficiency and step-size distance. Int $\mathbf{J}$ Biol Macromol 32:149-158

Worthington CR, Elliott GF (2005) Muscle contraction: a new interpretation of the transient behaviour of muscle. Int $\mathrm{J}$ Biol Macromol 35:265-268 